\title{
Pneumorrhachis with Spontaneous Pneumomediastinum and Subcutaneous Emphysema
}

\author{
Yan Song ${ }^{1}$, Lingfang $\mathrm{Tu}^{2}$ and Jianyong $\mathrm{Wu}^{1}$
}

Key words: pneumorrhachis, spontaneous pneumomediastinum, subcutaneous emphysema

(Inter Med 48: 1713-1714, 2009)

(DOI: 10.2169/internalmedicine.48.2256)

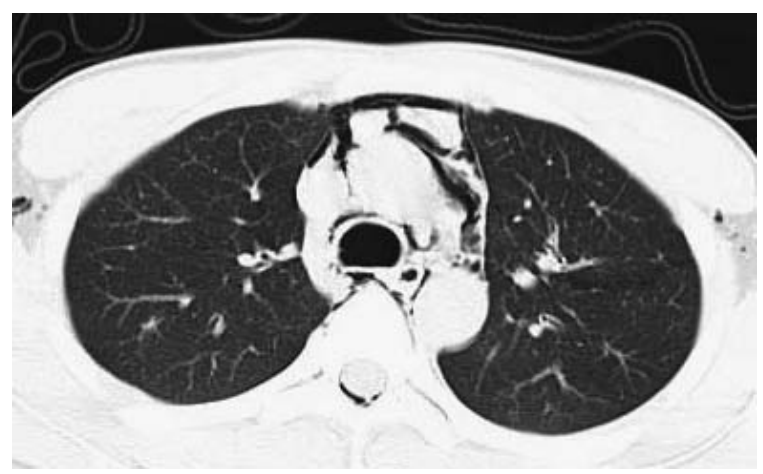

Picture 1. Chest computed tomography scan showing air collection in the mediastinum.

An 18-year-old male student was admitted to our hospital with complaints of a sudden onset of dyspnea and cough with numbness of double cruris for the previous 2 days. His vital signs were stable. Physical examination found crepitus on his right shoulder and the neck. The blood gas analysis was normal. A chest radiograph showed subcutaneous emphysema and pneumomediastinum. A computed tomographic scan of the chest was performed for further evaluation, which revealed air collection in the mediastinum (Picture 1) and air within the spinal canal (Picture 2). Thus, the patient was diagnosed as pneumorrhachis with spontaneous pneumomediastinum and subcutaneous emphysema. The patient was given the antitussive drug dextromethorphan (45 $\mathrm{mg}$ per day) to control the cough. The cough and the numbness of the cruris were gradually relieved. A repeat computed to-

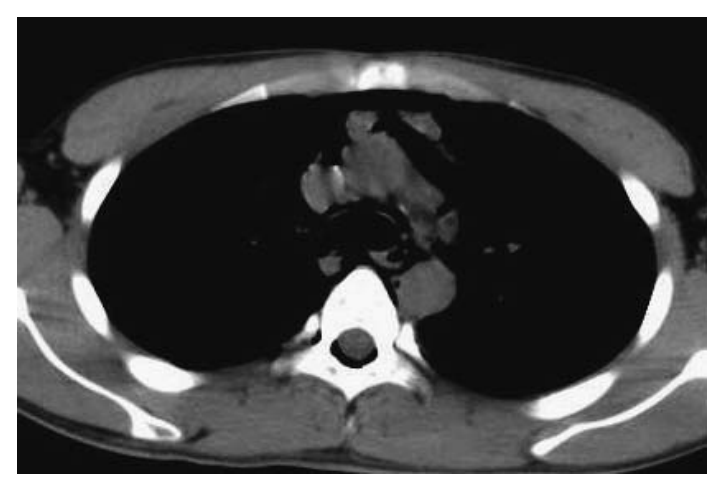

Picture 2. Chest computed tomography scan showing air within the spinal canal.

mographic scan of the chest after 7 days revealed complete resolution of pneumomediastinum as well as pneumorrhachis.

Spontaneous pneumomediastinum is an uncommon entity primarily affecting young adults and children (1). Pneumorrhachis is a rare complication of spontaneous pneumomediastinum (2). There have been only a few case reports of pneumorrhachis associated with spontaneous pneumomediastinum $(3,4)$. Epidural space pneumorrhachis with pneumomediastinum generally occurs by the following mechanism (5): air may infiltrate along fascial planes from the posterior mediastinum, through the neural foramina, and into the epidural space. Similar to the present case, two case reports showing an association with violent coughing have been reported $(6,7)$.

\section{References}

1. Caceres M, Ali SZ, Braud R, et al. Spontaneous pneumomediastinum: a comparative study and review of the literature. Ann Thorac Surg 86: 962-966, 2008.
2. Drevelengas A, Kalaitzoglou I, Petridis A. Pneumorrhachis associated with spontaneous pneumomediastinum. Eur J Radiol 18: 122123, 1994.

\footnotetext{
${ }^{1}$ Kidney Disease Center, The First Affiliated Hospital, College of Medicine, Zhejiang University, Hangzhou, China and ${ }^{2}$ Department of Pulmonary Medicine, The First Affiliated Hospital, College of Medicine, Zhejiang University, Hangzhou, China Received for publication March 12, 2009; Accepted for publication June 10, 2009 Correspondence to Dr. Jianyong Wu, wyj@mail.hz.zj.cn
} 
3. Gibikote S, Wray A, Fink AM. Pneumorrhachis secondary to traumatic pneumomediastinum in a child. Pediatr Radiol 36: 711-713, 2006.

4. Drolet S, Gagne JP, Langis P. Spontaneous pneumorrhachis associated with pneumomediastinum in a patient with diabetic ketoacidosis: an exceptional manifestation of a benign disease. Can $\mathbf{J}$ Surg 50: 225-226, 2007.

5. Ristagno RL, Hiratzka LF, Rost RC Jr. An unusual case of pneu- morrhachis following resection of lung carcinoma. Chest 121: 1712-1714, 2002.

6. Drevelengas A, Kalaitzoglou I, Petridis A. Pneumorrhachis associated with spontaneous pneumomediastinum. Eur J Radiol 18: 122123, 1994.

7. Tsuji J, Takazakura E, Terada Y, et al. CT demonstration of spinal epidural emphysema complicating bronchial asthma and violent coughing. J Comput Assist Tomogr 13: 38-39, 1989.

(C) 2009 The Japanese Society of Internal Medicine http://www.naika.or.jp/imindex.html 